\title{
A rasura não visúvel capturada em processo de escrita colaborativa na sala de aula
}

[...] a 'rasura branca': ela corrige, mas sem deixar traços, retomando o texto da página defeituosa em uma nova folha. Existem, portanto, rasuras imateriais cuja linha específica permanece invisível.

(Pierre-Marc de Biasi)

\section{Introdução}

ESTE TRABALHO BUSCA TRAZER À LUZ RASURAS QUE, SE OBSERVÁSSEMOS APENAS O PRODUTO FINAL - o texto produzido pelos alunos - e não o processo escritural, não seriam identificadas pelo pesquisador. Compartilham, de certa forma, algumas características daquelas rasuras mencionadas por Grésillon ${ }^{3}$ como "imateriais", não visíveis ao primeiro olhar, ou "rasuras brancas", para retomar a epígrafe de Biasi $^{4}$ acima, cujas linhas permanecem invisíveis.

As ocorrências desse tipo de rasura estão diretamente relacionadas ao fato do texto não guardar as marcas de seu processo. Conforme Leblay ${ }^{5}$ "buscar compreender o processo de textualização a partir do produto seria uma ilusão", pois o percurso da criação textual é permeado de fatores que lhe são inerentes: idas e vindas, apagamentos, inserções, pausas, hesitações. É nesse sentido que podemos dizer que o processo de escritura contém a memória de sua própria gênese e permite desvendar o DNA do texto. Por isso, como afirma Grésillon, "A gênese é irredutível ao texto, [e este] é impotente para restituí-la" .

Através do registro em tempo real de um processo de escrita colaborativa realizado em sala de aula por meio de uma ferramenta tecnológica denominada Sistema Ramos, buscamos compreender, analisar e descrever os momentos em que essas rasuras são inscritas e apontar para o fato amplamente demonstrado pela Genética Textual de o produto não ser uma imagem fiel do processo.

Desse modo, para se avançar pouco a pouco no saber sobre como alunos recém alfabetizados criam seus textos, desde o planejamento até dá-lo como pronto, acabado, seguir as rasuras pode ajudar a reconstruir seu percurso genético. Elas são marcas expoentes de uma operação metalinguística sobre o que está sendo linearizado, indicando um retorno reflexivo sobre

${ }^{1}$ Professora vinculada à Faculdade de Letras - FALE/UFAL, ao Programa de Pós-Graduação em Linguística e Literatura PPGLL e ao Laboratório do Manuscrito Escolar - LAME.

${ }^{2}$ Pesquisador do CNPq, professor vinculado ao Centro de Educação - CEDU/UFAL, ao Programa de Pós-Graduação em Linguística e Literatura - PPGLL, ao Programa de Pós-graduação em Educação - PPGE e coordenador do Laboratório do Manuscrito Escolar - LAME.

${ }^{3}$ GrÉSILLON, A. Elementos de crítica genética: ler os manuscritos modernos. Porto Alegre: Editora da UFRGS, 2007.

${ }^{4}$ BIASI, P-M de. Qu'est-ce qu'une rature? In: Bertrand Rougé (ed). Ratures et repentirs, actes du V Colloque du CICADA, 1994. PAU: Publications de l'Université de Pau, 1994.

${ }^{5}$ LEBLAY, C. Le temps de l'écriture. Genèse, durée, representations. Leblay, Christophe Le temps de l'écriture. Jyväskylä : University of Jyväskylä, 2011, p. 22.

${ }^{6}$ GRÉSILLON, A. Elementos de crítica genética: ler os manuscritos modernos. Porto Alegre: Editora da UFRGS, 2007 , p. 37. 
o já escrito. Elas também podem indicar "pontos de tensão" entre o que foi inscrito e o que o escrevente reconheceu como diferente, resultando na retirada, no acréscimo, na alteração ou modificação de diferentes objetos textuais do manuscrito em curso. Como diz Willemart ${ }^{8}$, a rasura "assinala em primeiro lugar uma atitude negativa, um 'não gosto disso', uma impressão de falta ou de falha na escritura que empurra a mão para suprimir a escrita anterior por uma razão muitas vezes desconhecida pelo próprio escritor”. Na sala de aula, a rasura permite conhecer sobre o que o aluno está refletindo, em que está avançando, o que é preciso reforçar.

O estudo da gênese escritural exige uma abordagem interdisciplinar e, até mesmo, transdisciplinar ${ }^{9}$. Neste caso, a partir da Genética Textual, não podemos prescindir da Linguística da enunciação e da Psicologia cognitiva ${ }^{10}$ para compreendermos as complexidades subjacentes de um processo de escrita. A Genética Textual nos provê de conceitos e métodos para reconstituir a história do texto in statu nascendi. O aporte da Psicologia Cognitiva nos ajuda a entender de que forma a interação imposta pela escrita em colaboração promove a revisão (e, consequentemente, a rasura) na medida em que produz conflito cognitivo e, portanto, a necessidade de os alunos reverem e integrarem diferentes pontos de vista ${ }^{11}$.

Na parte que segue delimitaremos melhor a questão que será aqui desenvolvida, bem como descreveremos a ferramenta que utilizamos para coletar os dados. Esperamos que, ao final do artigo, consigamos evidenciar, a partir das rasuras não visíveis, toda a complexidade e o dinamismo de um processo de escritura.

\section{A rasura não visível capturada no ato da inscrição}

Ao falarem sobre rasura imaterial ou rasura branca, Grésillon ${ }^{12}$ e Biasi ${ }^{13}$ referem-se a reescritas que ocorrem em versões sucessivas cujas alterações só podem ser verificadas quando se compara diferentes versões. Entretanto, a rasura da qual nos propomos a falar aqui é aquela que não deixa vestígios porque não se trata de alterações realizadas de uma versão para outra, seja porque o escrevente inseriu uma letra entre uma palavra e outra, um sinal de pontuação onde antes não havia nada, ou, até mesmo, reescreveu melhor (ou sobre) uma letra sem que se pudesse ser percebido. A importância de se mostrar o que

${ }^{7}$ CALIL, E. ; Del RE, A. Análise multimodal de uma história inventada: o caso da onomatopeia visual. Revista da ANPOLL, v. 2, p. 12-38, 2009.

${ }^{8}$ WILlEMART, P. Do sentido ao corpo: a rasura. Corpo e sentido. S. Paulo: Unesp, 1996, p. 156.

${ }^{9}$ Sobre a relação da Genética Textual com outras ciências, Anokhina chega mesmo a afirmar: "A crítica genética francesa [...] fez avanços notáveis na compreensão da gênese das escrituras das obras literárias. No entanto, resta a esperança de que um dia a crítica genética realmente encontre as ciências cognitivas e que uma nova disciplina surja centrada no estudo dos processos subjacentes à escrita: a crítica genética cognitiva. Espero que esta reflexão sobre o processo de antecipação por meio da observação dos rascunhos dos escritores ajude a lançar as bases dessa nova disciplina" (2018, p. 130).

${ }^{10}$ Grunig (2002) considera que já é tempo de os linguistas correlacionarem suas teorias com os achados e as observações feitas pelos neuropsicolinguistas, para que avanços possam ser obtidos e na medida em que um escrevente não pode escapar aos órgãos que entram em ação quando ele escreve.

${ }^{11}$ BosCOLO, P.; ASCORTI, K. Effects of Collaborative Revision on Children's Ability to Write Understandable Narrative Texts. In: Allal, L., ChANQUOY, L., LARgy, P. (eds) Revision Cognitive and Instructional Processes. Studies in Writing, vol 13. Springer, Dordrecht, 2004.

${ }^{12}$ GRÉSILLON, A. Elementos de crítica genética: ler os manuscritos modernos. Porto Alegre: Editora da UFRGS, 2007.

${ }^{13}$ BIASI, P-M de. Qu'est-ce qu'une rature? In: Bertrand Rougé (ed). Ratures et repentirs, actes du V Colloque du CICADA, 1994. PAU: Publications de l'Université de Pau, 1994. 
chamamos de "rasura não visível" ${ }^{14}$ reside no fato de que nem toda ferramenta que busque capturar o processo consegue resgatar esse tipo de rasura, o que acaba obliterando parte da complexidade e da riqueza de um processo escritural.

A identificação do objeto textual que foi inscrito e linearizado na superfície do suporte (folha de papel ou tela de computador, por exemplo) envolve o reconhecimento de que esse objeto textual (grafia, letra, palavra, frase, parágrafo...) pode ou deve ser diferente do que foi realmente escrito. Essa modificação pode ser feita apagando elementos gráficos e/ou linguísticos (objeto textual), substituindo-os, excluindo-os, adicionando outro objeto textual ou deslocando sua posição.

Esses aspectos da revisão textual alinham-se com o que Chanquoy descreve como "um exame do texto já produzido, que envolve releitura, eventualmente seguida de correções ou modificações, que envolvem edição"15. Isso envolve duas ações interligadas: a ação de reler e avaliar (rever, reexaminar) o que foi escrito e a ação de fazer uma mudança (revisar, conforme o modelo de escrita de Hayes e Flower, 1980). Claro, o reexame pode ocorrer sem uma revisão ou algum tipo de rasura na superfície do suporte e tanto o reexame quanto a revisão podem ocorrer online, durante as etapas de geração do texto.

A maioria das pesquisas sobre revisão analisou as mudanças evidenciadas nos textos finais ${ }^{16}$ e não a análise temporal das mudanças feitas durante a produção do texto. A este respeito, o estudo de Camps et $_{\text {al }}{ }^{17}$ é distinto e relevante na medida em que explora a situação da escrita colaborativa para considerar as decisões de escrita tomadas durante o processo de escrita. A captação de áudio da fala ao lado da escrita permitiu a identificação das reformulações orais e das atividades metalinguísticas estabelecidas durante o diálogo entre os alunos que escreveram juntos. Porém, a análise dessas reformulações orais não considerou os rasuras associadas às atividades metalinguísticas: por exemplo, se havia relação entre as ocorrências de rasuras e as atividades metalinguísticas verbalizadas.

A melhor maneira de compreender um processo de escrita é observar um escrevente em ação. Resgatar esse DNA do texto não é, no entanto, tarefa fácil e há vários protocolos e programas que se propõe a isso até o momento ${ }^{18}$. O método de captura que utilizamos leva em consideração a ecologia da sala de aula, isto é, as condições didáticas e interacionais sob as quais o texto é construído. O Sistema Ramos (SR) realiza uma captura multimodal (visual, sonora e escrita) de todo o processo, registrando em tempo real o áudio com o diálogo entre os alunos, o vídeo e o traçado da escrita "se fazendo", como é possível observar através da imagem abaixo:

${ }^{14}$ QUEIROZ, J.; CALIL, E. Rasura escrita não visível: o que os processos revelam? In: Revista Miguilim - revista eletrônica do Netlli, v. 8, n. 3, set-dez 2019.

${ }^{15}$ Chanquoy, L. Revision Process. In: Beard, Roger; Myhill, D.; Rilley, J.; Nystrand, M.. The SAGE Handbook of Writing Development, London: SAGE publications, 2009, p. 80.

${ }^{16}$ Roullier, Y. Collaborative revision and metacognitive reflection in a situation of narrative text production. In G. Rijlaarsdam (Ed.), (Series Ed.), Allal, L., Chanquoy, L., LARgy, P. (Vol. Eds.), Studies in Writing, Volume 13: Revision: Cognitive and instructional processes (pp. 171-187). Dordrecht: Kluwer Academic Publishers, 2003.

${ }^{17}$ CAMPS, A.; RiBS, T; GUASCH, O \& Milian, M. Metalinguistic activity: the link between writing and learning to write. In A. Camps, \& M. Milian (Eds.), Metalinguistic Activity in Learning to Write. Amsterdam: Amsterdam University Press, 2000.

${ }^{18}$ Um destes métodos é o think aloud, técnica amplamente usada nos anos 80 e que tem como método o registro em áudio do protocolo verbal de um único escrevente experiente, enquanto escrevia um texto. Esta técnica foi amplamente utilizada nos anos 80. Há também, dentre outros, o Gênese du Texte, usado com alunos e em contextos escolares. 


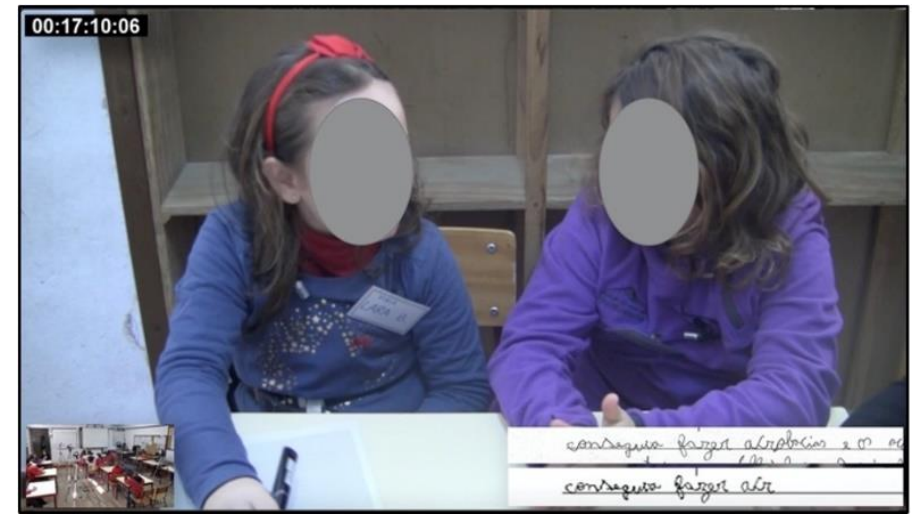

Imagem 1: A escrita "se fazendo", extraída de filme sincronizado pelo SR. Fonte: Laboratório do Manuscrito Escolar, 2015.

Como pode ser observado no canto inferior direito, na primeira linha, aparece um trecho do texto já escrito e, logo abaixo, a escrita "se fazendo", acompanhada do diálogo que ocorre entre as alunas. Isso tornou-se possível porque o SR é um sistema de captura multimodal que reúne alguns dispositivos: uma folha com micropontos, uma caneta smartpen com câmera infravermelha na ponta, que captura o movimento na folha de papel, um microfone de lapela e um minigravador digital acoplado à cintura de cada um dos alunos, além de uma câmera fixada à mesa de trabalho dos alunos por um braço articulado. Uma câmera com lente grande angular posicionada ao fundo da sala de aula também registra todo o movimento do professor e dos alunos. Como resultado, temos a geração de um filme sincronizado que oferece ao pesquisador informações sobre o produto final registrado na folha de papel; o manuscrito em curso, registrado pela caneta inteligente; o diálogo entre os alunos e o professor, capturado pelo gravador digital ${ }^{19}$ e posteriormente transcrito.

A utilização do SR em situações de escrita colaborativa ${ }^{20}$ nos dá acesso, então, aos índices materiais para reconstituirmos cronologicamente a redação do texto, de modo que a mínima interrupção no fluxo da escrita, através de pausas, reformulações, hesitações, dúvidas, discordâncias, explicações, justificativas dos alunos sobre o que deve ou não ser inscrito no manuscrito em construção é capturada. Gaulmyn ${ }^{21}$, ao falar sobre as trocas conversacionais que ocorrem em episódios de escrita colaborativa afirma que elas testemunham

[...] os processos cognitivos de realização de uma tarefa, graças à interação que exige que sejam explicitados para o outro. Assim, ao invés de estudar a escrita apenas na forma dos produtos coletados após o trabalho do escritor, podemos compreender o processo de co-escrita por meio do registro das palavras dos escritores e da gênese do texto tal como é inscrito na página ou na tela.

Vale apontar que qualquer atividade reflexiva sobre o oral não modifica o que já foi dito, embora possa modificar os seus efeitos, isto é, cada retorno sobre o oral produz um acréscimo, sempre adiante, na linha temporal. Se o eixo temporal, cronológico, é irreversível no que concerne à oralidade, o espaço gráfico da folha é reversível, na medida em que é sempre

${ }^{19}$ CALIL, E. Sistema Ramos: método para captura multimodal de processos de escritura a dois no tempo e no espaço real da sala de aula. In: Revista ALFA, n. 63, vol.1, 2019.

${ }^{20}$ A escrita colaborativa é chamada por Gaulmyn et al (2001) de "redação conversacional". São descritas pela autora como "situações privilegiadas em que se observa tanto a escrita nascer da oralidade, quanto a oralidade criar a escrita" (Gaulmyn, 2001, p. 09).

${ }^{21}$ GAULMYN, M-M.; BOUCHARD, R.; RABATEL, A. Le processus rédactionnel: écrire à plusieurs voix. Paris: L'Harmattan, 2001, p. 32. 
possível apagar, anular, inserir, deslocar e o produto será lido após o processo concluído. É possível, inclusive, reformular sem que se altere a ordem dos demais elementos gráficos, através de pequenas inserções.

Se a sucessividade é condição da oralidade em seu desenrolar temporal, na escrita, "entre o ponto de partida e o de chegada convencionais, não é apenas um tempo que decorre, mas um campo espacial que se abre", segundo Mahrer ${ }^{22}$. Para ReyDebove $^{23}$, "a linearidade temporal do som deixa traços apenas na memória fugaz do alocutário, enquanto a linearidade espacial conserva concretamente a enunciação e permite uma leitura retroativa, uma retomada a partir de qualquer sequência pelo leitor", de modo que não podemos modificar a linearidade temporal da mesma maneira como modificamos a espacial.

Assim, qualquer reformulação no oral fica obrigatoriamente integrada à enunciação, ao passo que quase nunca a modificação em um texto escrito faz parte do texto acabado. Neste sentido, apenas através de uma tecnologia que registre no tempo a realização do oral e do escrito é que se é possível estabilizar a "volatilidade" do oral e observar a reversibilidade do suporte gráfico. É isso que este estudo propõe: através de uma análise microgenética, amparada pela Genética Textual e propiciada pelo Sistema Ramos. Com suportes teóricos vindos da Linguística da Enunciação e da Psicologia cognitiva, analisamos rasuras que, realizadas em momentos de revisão que ocorreram tanto durante a produção textual, quanto após o texto já concluído, apontam para a grande complexidade de um processo de escritura, muito para além do que pode ser visto a olho nu.

\section{Metodologia}

O corpus a ser analisado foi extraído do Dossiê Criar e Recrear, resultado do desenvolvimento do "Projeto Criar e Inventar: meus primeiros contos" (2013) em uma turma de $1^{\circ}$ ano do ensino fundamental, com alunos recém-alfabetizados. Várias díades tiveram seus processos de escrita registrados pelo SR e o processo que será aqui analisado foi produzido pelas alunas Aline e Lara (nomes fictícios), ambas com quase 7 anos de idade. As alunas foram instruídas a criar uma narrativa ficcional e a produzida pela díade aqui analisada foi "O castelo asombrado" (sic).

Nestes processos de escrita colaborativa realizados por díades em sala de aula, a posse da caneta se alterna entre os alunos e, neste processo, a aluna Aline foi a responsável por controlar e oficializar o resultado do que haviam combinado anteriormente e sua companheira se encarregou de acompanhar, "iniciar novas proposições e, eventualmente, de ditá-las"24. No entanto, a ação do par vai além de ditar e/ou fazer "novas proposições". Frequentemente, é o par colaborador que observa um erro gráfico ou ortográfico, questiona e correlaciona o que foi combinado com o que está sendo escrito e sugere novas ideias.

O protocolo estabelecido para a condução da atividade é primeiramente a organização da turma em díades e a definição de quem, na dupla, ficará encarregado por escrever a história e quem ficará responsável por acompanhar a escrita, lembrando o que foi combinado, observando, sugerindo, etc. Normalmente, há uma alternância na posse da caneta a cada processo. Logo após, a professora expõe a consigna e solicita que as duplas combinem previamente a história. Após o momento da combinação, as duplas recebem a caneta e a folha com micropontos e passam ao momento da linearização (ou tradução). Ao final, a professora solicita que os alunos releiam e façam as alterações finais, se assim desejarem (momento da revisão).

\footnotetext{
${ }^{22}$ MAHrer, R. Écrire et parler. Quelques préalables théoriques. Genesis, 39, 2014, p. 37.

${ }^{23}$ ReY-Devove, J. Pour une lecture de la rature. In: La genèse du texte: les modèles linguistiques. Paris: Ed. du CNRS, 1987, p. 108.

${ }^{24}$ Apothelóz, D. Progression de texte dans les redactions conversationnelles: les techniques de la reformulation dans la fabrication du texte. In: MONDADA, L.; BOUCHARD, R. (ed.). Les processus de la rédaction collaborative. Paris: L'Harmattan, 2005, p. 172.
} 
A despeito das fases do protocolo de coleta, a análise de processos escriturais de alunos do fundamental nos mostram ${ }^{25}$ que a revisão ocorre em todas as fases, desde a combinação até o momento em que a tarefa é dada como concluída, o que é corroborado por vários estudos. Faigley e Witte ${ }^{26}$ sugerem que os escreventes vão e voltam durante toda a atividade de composição e que os escritores mais experientes frequentemente revisam o que escreveram e fazem alterações enquanto estão gerando um texto. Aceita-se amplamente hoje que as fases dos processos cognitivos envolvidos na composição textual não são lineares, como inicialmente parecia indicar o modelo proposto por Flower e Hayes ${ }^{27}$. Sommers ${ }^{28}$, por exemplo, mostrou que a revisão não ocorre apenas no fim do processo (momento da "correção"), mas que se trata de um processo constante de "re-visão" que continua enquanto os escreventes estão compondo.

Nossa análise destacará pontos de tensão que se caracterizam pelo retorno sobre um determinado objeto textual, o reconhecimento de algo que precisa ser modificado, seguido ou não por comentários entre as alunas. Quando não há comentários, o retorno pode ser identificado nas rasuras sobre o que já foi inscrito e linearizado.

\section{A rasura não visível em processo de escrita colaborativa}

Abaixo apresentamos o manuscrito produzido pelas alunas e, na sequência, um quadro com todas as rasuras não visíveis produzidas durante o processo de escrita:

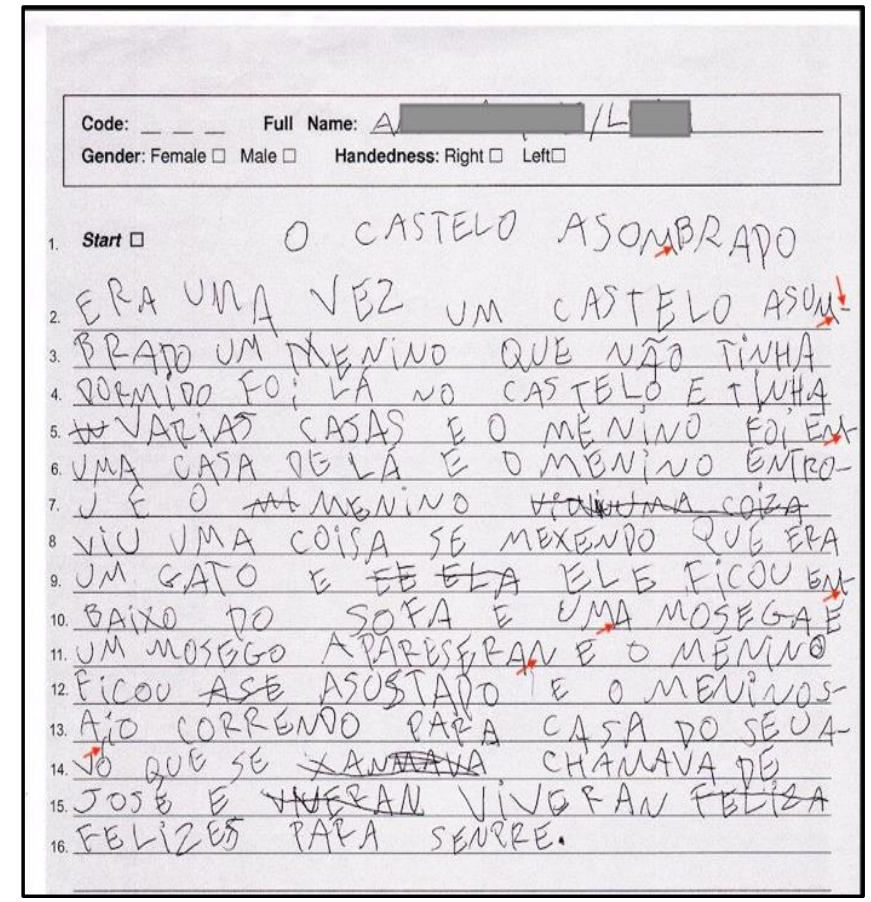

Imagem 2: texto "O castelo asombrado"

Fonte: Laboratório do Manuscrito Escolar, 2013.

${ }^{25}$ Felipeto, C; NAVArro, R. A pausa em processo de escrita colaborativa registrado em tempo real no primeiro ano do ensino fundamental. Revista Leitura n. 67, Maceió, 2020.

${ }^{26}$ FAigley, L.; WitTE, S. Analysing revision. College Composition and Communication, 32, 1981, p. 400-414.

${ }^{27}$ FLOWER, L., \& HAYES, J. A. A cognitive process theory of writing. College Composition and Communication v. 32, n.04, 1981.

${ }^{28}$ Sommers, N. (1978). Response to Sharon Crowley. Components of the Composing Process. College Composition and

Communication, 29 (2), 1978. 
O manuscrito porta todas as rasuras escritas que foram produzidas pelas alunas. Exceto as inconsistências inerentes ao traçado de alunos nesta faixa etária e devidas, também, ao fato de estarem escrevendo com uma caneta digital, todas as rasuras não visíveis estão marcadas com setas, totalizando oito rasuras não visíveis.

Já o quadro abaixo traz uma descrição completa do momento cronológico em que cada rasura foi feita, o "antes" e o "depois", com o diálogo entre as alunas referente a esse momento.

\begin{tabular}{|c|c|c|c|c|}
\hline \multicolumn{5}{|c|}{ Quadro 1: Rasuras não visíveis } \\
\hline $\begin{array}{l}\mathrm{N} . \\
\text { rasura }\end{array}$ & \multicolumn{2}{|c|}{$\begin{array}{l}\text { Rasura não visível } \\
\text { Antes e Depois }\end{array}$} & \multirow{2}{*}{\begin{tabular}{|l|} 
Tempo* \\
$08^{\prime} 29^{\prime \prime}$
\end{tabular}} & \multirow{3}{*}{$\begin{array}{l}\text { Diálogo } \\
\text { Obs.: o nome sublinhado é de quem está escrevendo. } \\
\text { Rasura feita quando Lara chama a atenção para a escrita de "ASUM", } \\
\text { na linha } 2 . \\
\text { Ver diálogo abaixo. }\end{array}$} \\
\hline \multirow{2}{*}{$\begin{array}{c}\mathbf{1} \\
\mathrm{L} .1\end{array}$} & \multicolumn{2}{|c|}{ A O CASTELO ASONBRAPO } & & \\
\hline & $\mathrm{D}$ & O CASTELO ASOMBRAPO & $09^{\prime} 10^{\prime \prime}$ & \\
\hline \multirow{2}{*}{$\begin{array}{l}2 \\
\text { L. } 2\end{array}$} & A & $A$ & $09^{\prime} 02^{\prime \prime}$ & \multirow{3}{*}{$\begin{array}{l}\text { 188. A: E...ra [ERA] u...ma [UMA] vez [VEZ] um [UM] cas...te...lo } \\
\text { [CASTELO] assom [ASUN]... } \\
\text { 189. L: Assum? Assom! } \\
\text { 190. A: Assom.... assom!... (Alice acrescenta uma "perna" no "N" de } \\
\text { "ASONBRADO" do título e no "N" de "ASUN", linha 2, } \\
\text { transformando-os em "M" [M]) Assim? } \\
\text { 191. L: Isso. } \\
\text { 192. A: Assom (Alice escrevendo o "B" de "assombrado" na outra } \\
\text { linha [B], eu tava... } \\
\text { 193. L: Esqueceu o tracinho. } \\
\text { 194. A : Aqui? (Alice retorna à linha anterior e faz o tracinho [-]) } \\
\text { 195. L: Aham. }\end{array}$} \\
\hline & $\mathrm{D}$ & & 09'12" & \\
\hline $\begin{array}{c}3 \\
\text { L. } 2\end{array}$ & $\mathrm{D}$ & A & 09'19" & \\
\hline \multirow{2}{*}{$\begin{array}{c}4 \\
\text { L. } 5\end{array}$} & $\mathrm{~A}$ & $E$ & $11 ' 22 "$ & \multirow{2}{*}{ 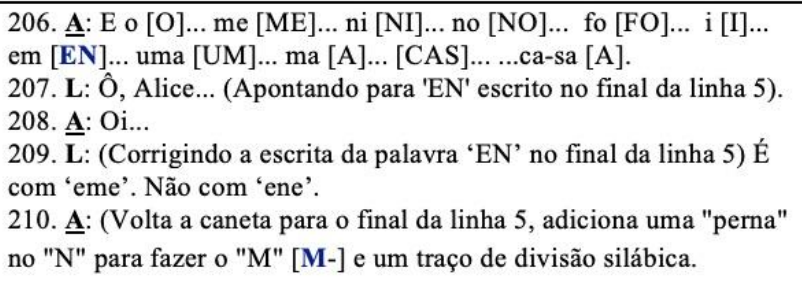 } \\
\hline & $\mathrm{D}$ & $E$ & $11^{\prime} 36^{\prime \prime}$ & \\
\hline \multirow{2}{*}{$\begin{array}{l}\mathbf{5} \\
\text { L. } 9\end{array}$} & A & Éç0 $5 \mathrm{ON}$ & $14^{\prime} 38^{\prime \prime}$ & \multirow{2}{*}{$\begin{array}{l}\text { 235. A : E ele [ELE]::: fiii:: [FI] ...cou [COU] em [EN] (Alice } \\
\text { percebe que fez o "N" ao invés do "M" e diz: "de novo!!". Acrescenta } \\
\text { uma "perna" para fazer o "M" e um traço de separação silábica) [M- } \\
\text { ]...bai... [BAI] xo [XO]. }\end{array}$} \\
\hline & $\mathrm{D}$ & ENt & $14 ' 40^{\prime \prime}$ & \\
\hline \multirow{2}{*}{$\begin{array}{l}6 \\
\text { L. } 10\end{array}$} & A & MOSEGA & $15^{\prime} 05^{\prime \prime}$ & \multirow[t]{2}{*}{$\begin{array}{l}\text { 235. } \text { A: e um }[\mathrm{UM}] \text { mo... [MO] ce...[SE] go [GA]::. morcega } \\
\text { (rindo). Eu fiz "morcega"... um... uma (Alice acrescenta o "A" à } \\
\text { palavra "UM") uma [UMA] morcega. }\end{array}$} \\
\hline & $\mathrm{D}$ & UMA MOSEGA & 15'14" & \\
\hline \multirow{2}{*}{$\begin{array}{l}7 \\
\text { L. } 11\end{array}$} & A & PARESERA $D$ & $15^{\prime} 46^{\prime \prime}$ & \multirow{2}{*}{$\begin{array}{l}\text { Rasura feita no momento da releitura e revisão: } \\
\text { 273. } \underline{\text { A: }} \text { (Lendo)... ele ficou embaixo do sofá e uma morcega e um } \\
\text { morcego apa:: apareceram (Alice faz um "N" em "APARESERA" } \\
\text { [APARESERAN]... ceram e o menino ficou assustado. }\end{array}$} \\
\hline & $\mathrm{D}$ & APARESERANE & $20^{\prime} 30^{\prime \prime}$ & \\
\hline \multirow{2}{*}{$\begin{array}{l}8 \\
\text { L. } 12\end{array}$} & A & $\sqrt{ } 0$ & 17'11" & \multirow{2}{*}{$\begin{array}{l}\text { 250. } \underline{\mathbf{A}}: \text {...rendo [RENDO] pa...ra [PARA] casa [CASA] do [DO] } \\
\text { se...u [SEU] a... [A] vô [VO] do seu avô. } \\
\text { 251. L: Tem um acento. } \\
\text { 252. } \underline{\mathbf{A}} \text { : Aqui? Avô (Alice coloca o acento [VÓ]). }\end{array}$} \\
\hline & $\mathrm{D}$ & 14. $\vee 0^{\circ}$ & $17^{\prime} 17^{\prime \prime}$ & \\
\hline
\end{tabular}


A análise de todo o processo mostra que, de um total de 22 rasuras produzidas, 8 delas são de rasuras não visíveis, ou seja, correspondem a $36 \%$ do total. Significa que $1 / 3$ de todas as rasuras produzidas não podem ser observadas a olho nu, ainda que em uma análise "a lupa" do manuscrito final.

Segundo a Psicologia cognitiva, há dois tipos principais de revisão: a primeira, as revisões internas, dizem respeito às revisões feitas mentalmente pelo escritor. Para essa forma de revisão, Chanquoy diz não ser possível investigar, a não ser através de técnicas como o think aloud, por exemplo. A segunda, as revisões externas, dizem respeito às mudanças (visíveis e não visíveis, como mostraremos) que são feitas no texto já escrito. Chanquoy afirma que a revisão "pode ser definida como um exame do texto já produzido, o qual envolve releitura, eventualmente seguida de correções ou modificações [e] é importante considerar a revisão mental, concebida como processo de avaliação, esclarecendo os pensamentos do escritor" 29. O processo de revisão pode focar uma letra ou uma palavra isolada, uma sentença, um parágrafo e, em um nível mais global, o texto todo.

Das rasuras não visíveis observadas no manuscrito escolar acima, duas delas foram feitas sem qualquer tipo de comentário durante sua realização. A primeira é a rasura 1, na linha 1 (título da história), em que Aline transforma o "N" de "Asonbrado" em "M", ficando "ASOMBRADO". Conforme diálogo exposto mais abaixo, Aline está escrevendo "ASUN" ("ASUMBRADO") no final da linha 2 quando Lara questiona "Assum? Assom!", ao que Aline responde: "Assom...Assom!" e, antes de fazer uma "perna" no "N" ao final da L2, olha para o título e, sem dizer nada referente a essa alteração, também acrescenta uma "perna" ao "N" de "ASONBRADO" do título.

No entanto, pelo diálogo e pela entonação que a fala de Lara imprimiu ao "o" de "Assom", ela parece se referir ao fato de a palavra estar sendo grafada com "U", ao invés de "O", mas Aline corrige os "N" do título e da L.2 e sua parceira Lara aceita essa alteração. A imagem abaixo mostra exatamente o momento em que Aline faz a rasura no "N" de "ASON" do título e logo após vai para o final da L.2:

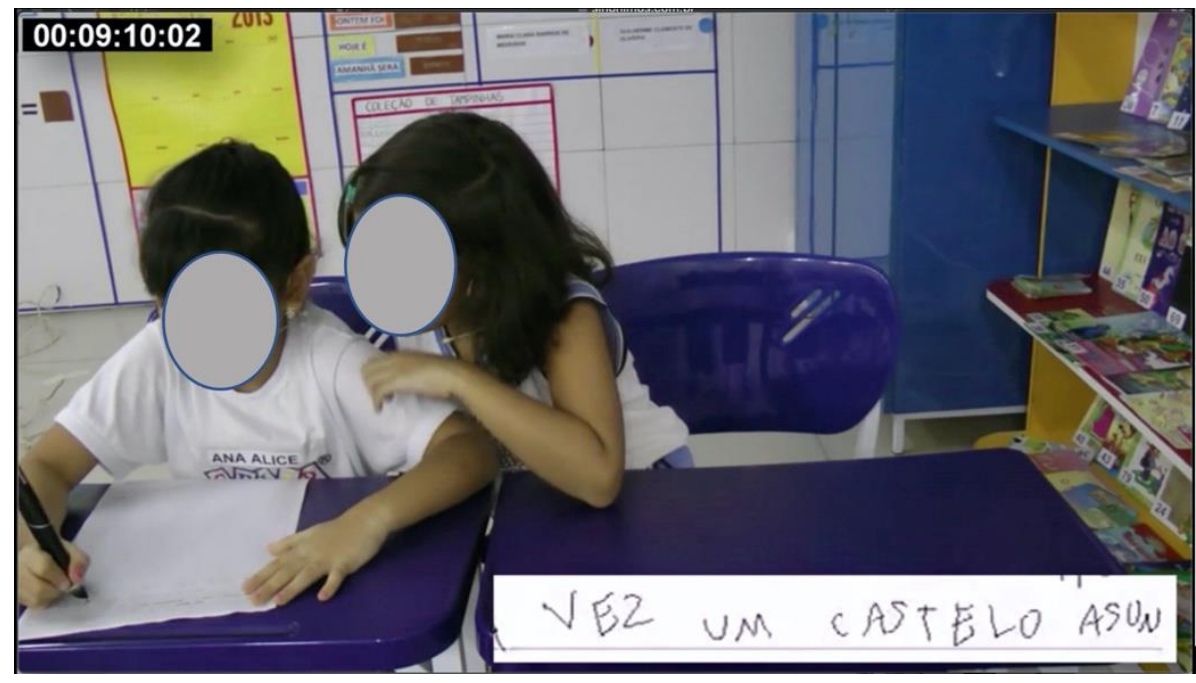

Imagem 3: rasura sem comentário

Fonte: Laboratório do Manuscrito Escolar, 2021.

${ }^{29}$ Chanquoy, L. Revision Process. In: BeARD, R.; Myhill, D.; RILEY, J.; NYSTRAND, M. The SAGE Handbook of Writing

Development, London: SAGE publications, 2009, p. 80-81. 
A segunda rasura sem comentário é a rasura 7, que ocorre na L.11. Trata-se de uma rasura feita no momento da revisão, isto é, quando já haviam terminado de escrever a história e a professora solicitou que fizessem a releitura.

Neste momento, Aline, que havia escrito "UM MOSEGO APARESERA E O MENINӨO" (L.11) está relendo e Lara a está ouvindo. Aline lê "apareceram" com a nasal bem audível, faz uma rápida pausa e adiciona um "N" ao lado do "A". Chamamos a atenção para o fato de Aline ter deixado um espaço maior entre "APARESERA" e "E", como pode ser observado no Quadro 1, comparando o antes com o depois; mas esse espaçamento também está presente em quase todas as linhas do texto. Como pode ser observado na imagem 2 mais acima é bastante possível inserir qualquer letra sem que os vestígios da adição possam ser percebidos.

Outro exemplo de rasura não visível, mas desta vez com comentário é a que Aline faz na L.10. Ela está falando o que escreve em voz alta: "um...mo...cego [MOSEGA] morcega! (rindo)". Nesse momento, ela se aproveita do espaço existente e acrescenta um "A" ao lado da palavra "UM" transformando-a em "UMA" (ver imagem 2 e quadro 1), sem que se perceba qualquer vestígio do retorno aí realizado.

Tanto a inserção do "N" em "APARESERA" e do "A" em "UM" podem ser consideradas adições? A adição, afirma Fabre (1990), diferentemente das outras operações, cria um novo onde nada havia; é a operação pela qual um elemento aparece, em uma versão, sem se substituir a nenhum elemento de uma variante anterior, de forma que uma sequência $A B$ pode se tornar $\mathrm{XAB}, \mathrm{AXB}$ ou ABX. (p. 159). A autora, no entanto, está se referindo a sequências lexicais. Em nosso caso, a sequência é no nível gráfico e podemos dizer que a sequência de letras AB tornou-se ABX. Nossos resultados coadunam com os de Fabre $(1990)^{30}$, quando observa que alunos de CE1 (correspondente ao $1^{\mathrm{o}}$ ano do fundamental brasileiro) adicionam sobretudo grafemas enquanto escrevem ou relêem seus rascunhos e, quando passam o texto "a limpo" as adições estendem-se sobretudo à pontuação e lexemas.

As rasuras não visíveis que ocorrem nas linhas 5 e 9 são rasuras que transformam o "N" em "M". Na L.5 é Lara que chama a atenção de Aline, ao dizer "Ô Aline..., é com 'm', não com 'n" e, na L.9, Aline percebe que fez um "N" ao invés de um "M" e diz: "de novo!". São casos de adição (de um traço) ou de substituição (de um "N" por um "M")? Vamos tentar avançar neste ponto através da análise de outra rasura, embora esta seja visível: a inserção de "VIU" entre duas palavras.

A rasura visível que ocorre na linha 7 (vide image 2) foi uma tentativa de Aline de inserir "VIU" entre "VIO" e "UMA". Nessa situação, Aline havia escrito "VIO" (ao invés de "VIU"), Lara chama sua atenção dizendo "VIU na verdade não é com 'O' não, é com 'U'" e Aline rasura a palavra "VIO", reescrevendo-a corretamente na sequência, e, quando reconhece que não coube no espaço, resolve rasurar tudo. Embora não seja o tipo de rasura objeto de nossa análise, esse exemplo nos ajuda a compreender que a rasura de adição para esses alunos recém alfabetizados é comumente feita com a inserção de letras, palavras e traços curtos ou sinais de pontuação em espaços os mais variados.

O exemplo acima configura um caso de substituição ou comutação, ou seja, a supressão de um elemento e sua substituição por um elemento novo (adição). A substituição, segundo Fabre (1990) ${ }^{31}$

é a operação pela qual um elemento é suprimido, ao passo que um outro é adicionado para se substituir ao primeiro, de modo que tanto um quanto outro funcionam como equivalentes em um certo contexto. [...] A rasura de substituição é por excelência uma relação entre dois termos tomados no eixo das seleções e ela estabelece entre eles uma equivalência formal ou mais ou menos estreita.

Ora, a substituição de "VIO" por "VIU", de um ponto de vista semântico, é do "mesmo" pelo "mesmo", e, do ponto de vista ortográfico, aponta para a relação de equivalência que [o] e [u] ocupam no eixo paradigmático (das seleções), sendo sua

${ }^{30}$ FABRE, C. Les brouillons d'écoliers ou l'entrée dans l'écriture. Grenoble: Ceditel / L'Atelier du Texte, 1990.

${ }^{31}$ Ibidem, p. 131, ênfase em itálico da autora. 
comutação bastante comum para alunos cuja ortografia encontra-se em fase de estabilização. Com relação ao nível linguístico em que a substituição ocorre nesta faixa etária, Fabre $(1990)^{32}$ afirma que ela é especializada no tratamento da ortografia, como é o caso da rasura acima.

Nos casos analisados, a rasura não visível pode ser produzida de duas maneiras: na primeira, opta-se por manter o segmento escrito e adjunto a ele, em sua continuidade, um outro traço é feito, modificando o segmento inicial. Por exemplo, as transformações gráficas do "N" em "M", como vimos mais acima. No segundo modo, um segmento é inserido em um espaço gráfico da folha sem alterar a grafia de nenhum outro elemento ao redor. Por exemplo, a adição do "N" em "APARESERA" e do "A" em "UM".

Tomemos uma rasura não visível do Quadro 1:

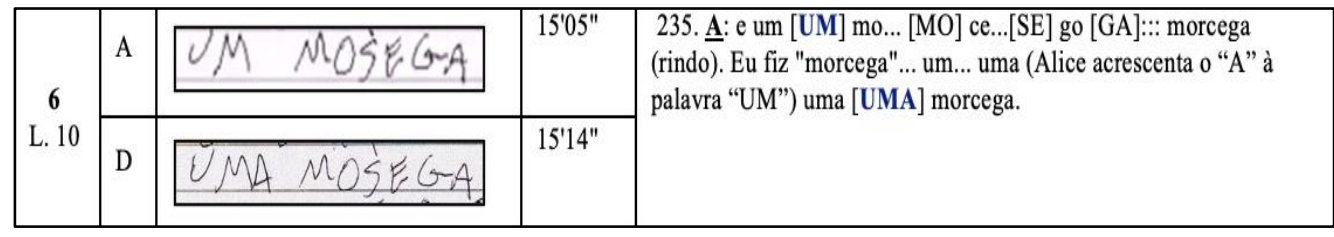

Imagem 4: embaralhamento das funções da rasura.

Fonte: Laboratório do Manuscrito Escolar, 2021.

No exemplo acima, trata-se de um caso de adição do "A"? ou da substituição do "UM" pelo "UMA"? O mesmo raciocínio vale para as outras rasuras não visíveis: trata-se de uma substituição do "N" pelo "M"? da adição de "O" (L.12) por "Ó", ao se adicionar o acento agudo? Observe-se que a rasura não visível embaralha as funções de substituição e adição.

\section{Palauras finais}

As rasuras não visíveis atacham-se fortemente a um caráter espacial e, ainda, motor: desde que haja espaço suficiente, desde que a mão acrescente algo sobre o que já estava lá, transformando-o, o movimento de retorno torna-se imperceptível. Por isso, como dissemos anteriormente, essas alterações só são possíveis no escrito e sob certas condições.

As rasuras não visíveis ocorrem no nível mais formal da língua, sobretudo ortográfico e não ocorrem nem no espaço interlinear, nem marginal. São realizadas a partir de uma "manobra", em que o escrevente se aproveita de um espaço existente. Essa forma de rasura parece estar limitada ao acréscimo de uma ou mais letras, sinais de pontuação e de acentuação. Ou daria continuidade a um traçado, transformando uma letra em outra. Retomando mais uma vez a epígrafe que deu início a esse trabalho, a rasura "branca" ou "imaterial", muito embora não deixe traços, pode ser observada cotejando uma versão com a outra. No caso das rasuras não visíveis, elas são inscritas sobre um mesmo manuscrito, mas não podem ser identificadas no produto, somente em seu processo, no registro fílmico do manuscrito em curso.

Não se trata de uma "rasura de sobrecarga"33 , em que o elemento substitutivo se inscreve sobre a palavra que ele substitui, misturando correção e palavra corrigida em um mesmo espaço. Parece não se tratar, também, de uma substituição "clássica", que implica uma dupla operação (supressão + adição), já que não ficam marcas da supressão. Essas rasuras ocorrem sempre valendo-se de um espaço onde antes não havia nada:

\footnotetext{
${ }^{32}$ Ibidem.

${ }^{33}$ BIASI, P-M de. Qu'est-ce qu'une rature? In: Bertrand Rougé (ed). Ratures et repentirs, actes du V Colloque du CICADA. PAU: Publications de l'Université de Pau, 1994, p. 07.
} 
- adicionando uma letra, um acento ou um traço e, por consequência, transformando um elemento, substituindo-o por outra coisa. Ex: UM > UMA / VO > VÓ / EN > EM .

- adicionando um sinal de pontuação, uma letra e, por consequência, transformando o sintagma. Ex: ASUM (BRADO) $>$ ASUM- >BRADO.

Neste sentido, propomos interpretar essas rasuras como sendo rasuras não visíveis que se servem das funções de adição e substituição. Elas não apagam, por um traçado, nenhum elemento anterior e, na sua continuidade ou contiguidade, adicionam uma letra, um traço, um sinal, para transmutá-lo, corrigí-lo.

Diz Biasi que "antes de se exprimir e de se inscrever sob a forma de um traçado, a rasura é uma operação intelectual que pode ser precedida, em alguns segundos de reflexão, por uma série considerável de formações verbo-mentais" ${ }^{34}$. Com relação à escrita colaborativa, podemos conhecer parte dessas formações verbo-mentais graças à interação e aos comentários que dela surgem. A rasura pode ser instigada pelos comentários do parceiro colaborador. Assim ocorreu com 4 das 8 rasuras não visíveis deste processo analisado. Das outras 4 rasuras produzidas por iniciativa da própria escrevente, 2 delas foram realizadas sem comentários, mas fica evidente a influência extretamente positiva da parceria de Lara sobre a escrita de Aline: Lara ajuda Aline a avançar em questões ortográficas, envolvendo acentuação, trocas previsíveis entre "N" e "M" ou entre "O" e "U", pontuação, além de alertar para a ausência de traços da separação silábica, como o da linha 9.

A análise microgenética, voltada para as minúcias da criação textual é coerente com o apoio teórico da Genética Textual. E, para que ela seja possível, o Sistema Ramos, articulado com a escrita em colaboração, favorece o exame detalhado dos processos cognitivos e interacionais, permitindo a apreensão cronológica das marcas deixadas (ou não) quando o aluno rasura o que foi já escrito. Isto porque, o SR, quando captura em áudio e vídeo a escrita colaborativa, dá acesso ao diálogo e a parte das "formações verbo-mentais" de que fala Biasi (1994), às atividades reflexivas realizadas pelos alunos. E, com a possibilidade de visualizar a "escrita se fazendo", mesmo em ausência de diálogo é possível vislumbrar momentos em que o aluno escrevente realiza alterações (perceptíveis ou não), deixando a nu todo o processo de escritura.

\section{Referências bibliográficas}

Allal, L., Chanquoy, L. Introduction: Revision revisited. In: G. Rijlaarsdam (Ed.), Revision: Cognitive and instructional processes (pp. 1-7). Dordrecht: Kluwer Academic Publishers, 2003.

Anokhina, O; IDMhand, F. La fabrique du texte à l'épreuve de la génétique. Paris: Éditions des archives contemporaines, 2018.

Apothelóz, D. Progression de texte dans les redactions conversationnelles: les techniques de la reformulation dans la fabrication du texte. In: MONDADA, L.; BOUCHARD, R. (ed.). Les processus de la rédaction collaborative. Paris: L'Harmattan, 2005.

BIASI, P-M de. Qu'est-ce qu'une rature? In: Bertrand Rougé (ed). Ratures et repentirs, actes du V Colloque du CICADA. PAU: Publications de l'Université de Pau, 1994.

Boscolo, P.; AsCorti, K. Effects of Collaborative Revision on Children's Ability to Write Understandable Narrative Texts. In: Allal, L., ChANQUOY, L., LARGy, P. (eds) Revision Cognitive and Instructional Processes. Studies in Writing, vol 13. Springer, Dordrecht., 2004.

${ }^{34}$ Ibidem, p. 03. 
CAlil, E.; Del RE, A. Análise multimodal de uma história inventada: o caso da onomatopeia visual. Revista da ANPOLL, v. 2, p. 12-38, 2009.

CALIL, E. Sistema Ramos: método para captura multimodal de processos de escritura a dois no tempo e no espaço real da sala de aula. In: Revista ALFA, n. 63, vol.1, 2019.

CAmPS, A.; Ribas, T; Guasch, O., \& Milian, M. Metalinguistic activity: the link between writing and learning to write. In: A. Camps, \& M. Milian (Eds.), Metalinguistic Activity in Learning to Write. Amsterdam: Amsterdam University Press, 2000.

Chanquoy, L. Revision Process. In: Beard, R.; Myhill, D.; Riley, J.; Nystrand, M. The SAGE Handbook of Writing Development, London: SAGE publications, 2009.

FABRE, C. Les brouillons d'écoliers ou l'entrée dans l'écriture. Grenoble: Ceditel / L'Atelier du Texte, 1990.

FAigley, L.; WitTE, S. Analysing revision. College Composition and Communication, 32, 1981, p. 400-414.

FELIPETO, C; NAVARRo, R. A pausa em processo de escrita colaborativa registrado em tempo real no primeiro ano do ensino fundamental. Revista Leitura n. 67, Maceió, 2020.

FLOWER, L., \& HAYES, J. A. A cognitive process theory of writing. College Composition and Communication v. 32, n. $04,1981$.

GAULMYN, M-M.; BOUCHARD, R.; RABATEL, A. Le processus rédactionnel: écrire à plusieurs voix. Paris: L'Harmattan, 2001.

GRÉSILLON, A. Elementos de crítica genética: ler os manuscritos modernos. Porto Alegre: Editora da UFRGS, 2007. GRUNIG, B-N. Linguistique et brouillons, dynamique et synchronization. Langages n. 147, 2002.

LEBLAY, C. Le temps de l'écriture. Genèse, durée, representations. Jyväskylä: University of Jyväskylä, 2011.

MAHRER, R. Écrire et parler. Quelques préalables théoriques. Genesis, 39, 2014, p. 29-49.

QueIROZ, J.; CALIL, E. Rasura escrita não visível: o que os processos revelam? In: Revista Miguilim - revista eletrônica do Netlli, v. 8, n. 3, set-dez 2019.

REY-DeVOVE, J. Pour une lecture de la rature. In: La genèse du texte: les modèles linguistiques. Paris: Ed. du CNRS, 1987.

Roullier, Y. Collaborative revision and metacognitive reflection in a situation of narrative text production. In: G. Rijlaarsdam (Ed.), Allal, L., Chanquoy, L., LARGY, P. (Vol. Eds.), Studies in Writing, Volume 13: Revision: Cognitive and instructional processes (pp. 171-187). Dordrecht: Kluwer Academic Publishers, 2003.

Sommers, N. Response to Sharon Crowley. Components of the Composing Process. College Composition and Communication, 29 (2), 209-211, 1978.

WILlemarT, P. Do sentido ao corpo: a rasura. Corpo e sentido. S. Paulo: Unesp, 1996. 